\title{
Impacts of duration of untreated psychosis on cognition and negative symptoms in first-episode schizophrenia: a 3-year prospective follow-up study
}

\author{
W. C. Chang*, C. L. M. Hui, J. Y. M. Tang, G. H. Y. Wong, S. K. W. Chan, E. H. M. Lee \\ and E. Y. H. Chen \\ Department of Psychiatry, The University of Hong Kong, Queen Mary Hospital, Pokfulam, Hong Kong
}

\begin{abstract}
Background. Cognitive impairment is a core feature of schizophrenia. Its relationship with duration of untreated psychosis (DUP), a potentially malleable prognostic factor, has been less studied, with inconsistent findings being observed in the literature. Previous research investigating such a relationship was mostly cross-sectional and none of those prospective studies had a follow-up duration beyond 2 years.
\end{abstract}

Method. A total of 93 Hong Kong Chinese aged 18 to 55 years presenting with first-episode schizophrenia-spectrum disorder were studied. DUP and pre-morbid adjustment were measured using a structured interview incorporating multiple sources of information. Psychopathological evaluation was administered at intake, after clinical stabilization of the first psychotic episode, and at 12, 24 and 36 months. Cognitive functions were measured at clinical stabilization, and at 12,24 and 36 months.

Results. DUP exerted differential effects on various cognitive domains, with memory deficits being the most related to DUP even when potential confounders including pre-morbid adjustment and sex were adjusted. Prolonged DUP was associated with more severe impairment in visual memory at clinical stabilization and verbal memory at 24 and 36 months. Further, patients with a long DUP were found to have worse outcomes on negative symptoms at 36 months. The effects of DUP on verbal memory remained significant even when negative symptoms were taken into consideration.

Conclusions. Our findings provided further supportive evidence that delayed treatment to first-episode psychosis is associated with poorer cognitive and clinical outcomes. In addition, DUP may specifically affect memory function and its adverse impact on verbal memory may only become evident at a later stage of the recovery process.

Received 1 June 2012; Revised 3 November 2012; Accepted 13 November 2012; First published online 7 December 2012

Key words: Cognitive impairment, duration of untreated psychosis (DUP), first-episode schizophrenia, negative symptoms, prospective follow-up.

\section{Introduction}

Duration of untreated psychosis (DUP) has been considered as a potentially modifiable prognostic factor of schizophrenia. The majority of studies examining DUP have focused on its relationships with clinical and functional outcomes, and they revealed that prolonged DUP predicts a higher level of symptoms, worse psychosocial functioning and poorer quality of life (Marshall et al. 2005; Perkins et al. 2005).

Cognitive impairment is a core feature of schizophrenia (Elvevag \& Goldberg, 2000). A substantial body of evidence has demonstrated that patients presenting with first-episode schizophrenia exhibit pronounced deficits across various cognitive domains,

* Address for correspondence: W. C. Chang, Department of Psychiatry, The University of Hong Kong, Queen Mary Hospital, Pokfulam, Hong Kong.

(Email: changwc@hku.hk) particularly in memory, attention and executive function (Mesholam-Gately et al. 2009). As cognitive dysfunction has consistently been shown to predict functional disability (Green et al. 2000) and remains an unmet therapeutic need due to its limited response to antipsychotic treatment (Goldberg et al. 2007), clarifications of correlates associated with cognitive impairment, in particular those being potentially malleable to interventions such as DUP, are of significant clinical relevance. Nonetheless, relatively few studies have been conducted to investigate the relationship between DUP and cognitive functions in schizophrenia. Among those few studies, some have indicated that prolonged DUP is related to more severe cognitive impairment (Scully et al. 1997; Amminger et al. 2002; Joyce et al. 2002; Lappin et al. 2007), while others have failed to find such a relationship (Hoff et al. 2000 ; Norman et al. 2001; Townsend et al. 2002; Ho et al. 2003; Addington et al. 2004; Rund et al. 2007; Barnes et al. 2008; Goldberg et al. 2009). 
Inconsistency in findings regarding the association between DUP and cognitive functions in schizophrenia may partly be attributed to methodological variations in sampling, measurements of DUP and outcome variables, choice of cognitive assessments administered, and lengths of follow-up. Of note, cognitive performance may change substantially from treatment initiation to the time when psychosis has been stabilized (Townsend et al. 2002). In addition, certain cognitive functions may improve over a longer period of time after the initial psychotic episode (Gold et al. 1999; Albus et al. 2002). On the other hand, most previous studies that addressed the relationship between DUP and cognitive functions were crosssectional with focus on initial presentation of the first psychotic episode (Hoff et al. 2000; Norman et al. 2001; Amminger et al. 2002; Joyce et al. 2002; Ho et al. 2003; Lappin et al. 2007). For those very few prospective longitudinal studies, their lengths of follow-up ranged from 4 months to 2 years only (Townsend et al. 2002; Addington et al. 2004; Rund et al. 2007; Barnes et al. 2008; Goldberg et al. 2009). In this regard, studies with such a short follow-up interval may fail to capture an evolving course of cognitive recovery, and hence its association with DUP in the early phase of the illness.

Discrepant findings have also been observed with respect to the relationship between DUP and negative symptoms. Whereas several past studies (Scully et al. 1997; Harrigan et al. 2003; Melle et al. 2008) and two meta-analyses (Marshall et al. 2005; Perkins et al. 2005) found that longer DUP predicted worse outcome on negative symptoms, other investigators revealed a lack of independent contribution of DUP on severity of negative symptoms when pre-morbid adjustment was taken into consideration (Harris et al. 2005; Jeppesen et al. 2008).

In this article, we present a prospective 3-year follow-up study in a representative cohort of Chinese patients having first-episode schizophrenia-spectrum disorder in Hong Kong with an aim to examine the influence of DUP on longitudinal trajectories of cognitive and clinical measures. DUP was measured using a standardized instrument incorporating multiple sources of information when patients first presented to treatment. The potential confounding effects of premorbid functioning on cognitive and clinical outcomes were adjusted to enable a better estimation of a unique contribution of DUP to these outcome measures.

\section{Method}

\section{Participants}

Participants were recruited from both out-patient and in-patient psychiatric units that provide service for a catchment area in Hong Kong with a population of approximately 1.3 million. A total of 138 patients aged 18-55 years who were consecutively diagnosed as having first-episode schizophrenia, schizophreniform disorder or schizo-affective disorder were included. Patients with known neurological disorder or learning disability were excluded from the study. Of the initial cohort, 93 subjects completed the 3-year follow-up, 40 defaulted, four committed suicide and one died of medical disease. There were no significant differences between completers and non-completers in sociodemographics, DUP, baseline symptom ratings and cognitive functions. Patients in this study were initially treated with low-dose first-generation antipsychotic medications. Among 93 subjects, 48 were first assessed in a medication-naive state, and the rest were evaluated within 7 days of starting antipsychotic treatment.

The current study was part of a prospective 3-year follow-up study in first-episode schizophreniaspectrum disorder patients and findings regarding persistent negative symptoms and cognitive predictors of relapse have been reported elsewhere (Chen et al. 2005; Chang et al. 2011). The study was approved by the local institutional review board and all of the subjects gave written informed consent before participation.

\section{Diagnostic, clinical and cognitive assessments}

Diagnostic assignment was based on a longitudinal approach taking into consideration that diagnostic change may take place over time (Chang et al. 2009). The 3-year diagnosis of each subject was determined according to Diagnostic and Statistical Manual of Mental Disorders, fourth edition (DSM-IV) criteria (APA, 1994) using all available information encompassing the whole follow-up period including the Chinese-bilingual Structured Clinical Interview for DSM-IV (Axis I, Patient version) (CB-SCID-I/P, So et al. 2003) administered at baseline and at 3 years, informant histories and medical records. A previous validation study showed that the CB-SCID-I/P yields reliable DSM-IV diagnoses in Chinese patients with psychotic disorders (So et al. 2003). Independent diagnostic assessments on a subset of the sample $(n=38)$ demonstrated a satisfactory concordance rate of $86 \%$.

Pre-morbid functioning was measured with the Premorbid Adjustment Scale (PAS; Cannon-Spoor et al. 1982) based on information obtained via interviews with patients and relatives. We only included childhood ( $\leqslant 11$ years) and early adolescence (12-15 years) periods for assessment to avoid any possible confounding with early symptoms because the onset of prodrome and psychosis usually occurs in 
late adolescence and early adulthood (Cassidy et al. 2010). The PAS total score was calculated by summing the scores on all items encompassing both childhood and early adolescence periods and dividing by the total possible score (score range 0 to 1 ; a higher score indicates lower functioning).

DUP, which was defined as the time interval between the onset of positive psychotic symptoms and treatment initiation, was assessed with the Interview for the Retrospective Assessment of the Onset of Schizophrenia (Häfner et al. 1992) incorporating information from patients, relatives and medical records. Positive symptoms were assessed using the Positive and Negative Syndrome Scale (PANSS; Kay et al. 1987) with intra-class correlation coefficient (ICC) being 0.83 for the positive symptoms subscale. The High Royds Evaluation of Negativity Scale (HEN; Mortimer et al. 1989) was employed to measure negative symptoms. It comprises six subscales and 18 items that are rated along an anchored five-point severity scale (range 0-4; a higher score indicates more severe negative symptoms). Validation of the HEN for use in Chinese schizophrenia patients has previously been reported (Chen et al. 1996). ICCs for the subscales ranged from 0.74 (Thought) to 0.85 (Speech). In this study, we only included four of the six subscales, i.e. Affect, Behaviour, Speech and Functioning subscales for analysis (Chang et al. 2011) as the remaining two, namely Thought and Appearance subscales, were more related to the disorganization dimension.

A comprehensive battery of cognitive assessments was administered to all subjects, comprising a logical memory test (Wechsler Memory Scale Revised; WMSR-HK, Hong Kong Psychological Society, 1989b), a visual reproduction test (WMS-R-HK), forward digit span (Wechsler Adult Intelligence Scale; WAIS-R-HK; Hong Kong Psychological Society, 1989a), semantic category fluency and the Modified Wisconsin Card Sorting Test (Nelson, 1976). General verbal intelligence was estimated at baseline using the information subscale from the WAIS-R-HK (Chen et al. 2005).

Psychopathological evaluation was conducted for each subject at intake, after clinical stabilization of the first psychotic episode (a mean of 42.6 days after initial assessment), and at 12, 24 and 36 months. To maximize cooperation and to reduce state effects of acute psychosis, the cognitive assessment undertaken when patients were clinically stabilized was regarded as the baseline cognitive measure. The cognitive assessment was re-administered to each subject at 12, 24 and 36 months. A group of healthy controls, matched for age, sex and educational level, were recruited via advertisements and were evaluated with the same battery of cognitive assessments as patients at baseline only. Research staff who administered symptom and cognitive assessments was blind to the DUP measure.

\section{Statistical analysis}

Differences between patients and matched controls on baseline cognitive functions were evaluated using the independent $t$ test. The patient sample was divided into short and long DUP groups based on median split at 180 days. Pre-morbid functioning, and sociodemographic and treatment characteristics between the two groups were compared using the independent $t$ test and $\chi^{2}$ test as appropriate. To compare symptom and cognitive outcomes between the two groups at each assessment time point, an analysis of covariance (ANCOVA) was performed with sex and PAS total score as covariates. Longitudinal changes in symptom ratings and cognitive deficits over 3 years were compared between the two DUP groups using a repeatedmeasures ANCOVA with time points as the withinsubject level, and sex and PAS total score as covariates. The Greenhouse-Geisser correction was used when the sphericity assumption was not met. All analyses were two-tailed and the level of significance was set at $p<0.05$.

\section{Results}

\section{Characteristics of the sample}

Of the 93 subjects who were followed up for 3 years, 84 completed DUP assessments and thus constituted the final sample of the study. The 84 subjects were predominantly single $(72.6 \%)$, and $42.9 \%$ were male. The mean age of the sample at intake was 31.5 years (S.D. $=9.5$, range 18-55 years) and the average educational level was 10.49 years (S.D. =3.0). The median DUP of the sample was 180 days and the mean was 473.7 days (S.D. $=786.4$, range $2-3650$ days). Diagnoses for the cohort were schizophrenia $(n=67)$, schizophreniform disorder $(n=12)$ and schizo-affective disorder $(n=5)$. There were no significant differences between subjects with a DUP measure and those without in sociodemographics, pre-morbid functioning, baseline symptom and cognitive measures, and treatment characteristics.

Table 1 summarizes sociodemographics, premorbid adjustment and treatment characteristics of the patient sample. Patients with a long DUP were significantly more likely to be male than those with a short DUP. Otherwise, no significant differences between the two groups among other variables were observed.

As shown in Table 2, there were no significant differences between patients and healthy controls in age, sex and educational level. Patients performed 
Table 1. Demographics, pre-morbid adjustment, baseline and treatment characteristics of patients with first-episode schizophreniaspectrum disorder

\begin{tabular}{|c|c|c|c|c|}
\hline Variable of interest & $\begin{array}{l}\text { Subjects with DUP } \\
<180 \text { days }(n=41)\end{array}$ & $\begin{array}{l}\text { Subjects with DUP } \\
\geqslant 180 \text { days }(n=43)\end{array}$ & $\begin{array}{l}\text { Statistics: } \chi^{2} \\
\text { or } t(\mathrm{df})\end{array}$ & $p$ \\
\hline \multicolumn{5}{|l|}{ Baseline sociodemographic and clinical characteristics } \\
\hline Mean age at entry, years (S.D.) & $31.5(10.2)$ & $31.5(8.9)$ & $-0.023(82)$ & 0.98 \\
\hline Male sex, $n(\%)$ & $13(31.7)$ & $23(53.5)$ & 4.1 & 0.044 \\
\hline Mean duration of education, years (S.D.) & $10.5(3.6)$ & $10.5(2.4)$ & $-0.001(82)$ & 0.99 \\
\hline Mean PAS total score (S.D.) & $0.34(0.1)$ & $0.36(0.1)$ & $-0.4(78)$ & 0.67 \\
\hline Mean DUP, days (s.D.) & $49(42.7)$ & $878.6(936.1)$ & $5.8(82)$ & $<0.0001$ \\
\hline \multicolumn{5}{|l|}{ Treatment characteristics } \\
\hline Mean CPZ equivalence at intake, $\mathrm{mg} /$ day (s.D.) & $219.4(615.4)$ & $139.3(195.5)$ & $0.8(82)$ & 0.42 \\
\hline Mean CPZ equivalence at clinical stabilization, $\mathrm{mg} /$ day (s.D.) & $405.4(427.9)$ & $304.9(317.6)$ & $1.2(82)$ & 0.22 \\
\hline Mean CPZ equivalence at year $1, \mathrm{mg} /$ day (s.D.) & $264.3(391.6)$ & $274.8(242.5)$ & $0.2(82)$ & 0.88 \\
\hline Mean CPZ equivalence at year $2, \mathrm{mg} /$ day (s.D.) & $293.9(452.9)$ & $245.0(249.7)$ & $0.6(82)$ & 0.54 \\
\hline Mean CPZ equivalence at year 3, mg/day (S.D.) & $233.3(346.4)$ & $228.8(233.8)$ & $0.07(82)$ & 0.94 \\
\hline Mean anticholinergic dose ${ }^{\mathrm{a}}$ at intake, $\mathrm{mg} /$ day (S.D.) & $0.7(1.7)$ & $1.2(2.1)$ & $-1.3(82)$ & 0.21 \\
\hline $\begin{array}{l}\text { Mean anticholinergic dose } \mathrm{a}^{\mathrm{a}} \text { at clinical } \\
\text { stabilization, } \mathrm{mg} / \text { day (s.D.) }\end{array}$ & $3.2(3.4)$ & $3.6(3.5)$ & $-0.6(82)$ & 0.55 \\
\hline Mean anticholinergic dose ${ }^{\mathrm{a}}$ at year $1, \mathrm{mg} /$ day (S.D.) & $2.2(2.9)$ & $2.9(2.8)$ & $-1.1(82)$ & 0.29 \\
\hline Mean anticholinergic dose ${ }^{\mathrm{a}}$ at year $2, \mathrm{mg} /$ day (s.D.) & $2.1(2.9)$ & $2.1(2.5)$ & $-0.08(82)$ & 0.94 \\
\hline Mean anticholinergic dose ${ }^{\mathrm{a}}$ at year $3, \mathrm{mg} /$ day (s.D.) & $2.2(2.8)$ & $2.0(2.6)$ & $0.4(82)$ & 0.68 \\
\hline On SGA at clinical stabilization ${ }^{\mathrm{b}, \mathrm{c}}, n(\%)$ & $1(2.4)$ & $1(2.3)$ & 0.001 & 0.99 \\
\hline On SGA at year $1^{\mathrm{b}, \mathrm{d}}, n(\%)$ & $4(9.8)$ & $3(7.0)$ & 0.2 & 0.71 \\
\hline On SGA at year $2^{\mathrm{b}, \mathrm{e}}, n(\%)$ & $5(12.2)$ & $8(18.6)$ & 0.7 & 0.55 \\
\hline On SGA at year $3^{\mathrm{b}, \mathrm{f}}, n(\%)$ & $7(17.1)$ & $8(18.6)$ & 0.3 & 0.86 \\
\hline
\end{tabular}

DUP, Duration of untreated psychosis; df, degrees of freedom; s.D., standard deviation; PAS, Premorbid Adjustment Scale; CPZ, chlorpromazine; SGA, second-generation antipsychotic; FGA, first-generation antipsychotic.

a Anticholinergic medication refers to benzhexol.

${ }^{b}$ Fisher's exact test was applied.

${ }^{c}$ Out of the 84 subjects, two took SGA medication at clinical stabilization, with all on risperidone. The remaining subjects were treated with a FGA.

${ }^{\mathrm{d}}$ Out of the 84 subjects, seven took SGA medication at year 1, with five on risperidone and two on olanzapine. The remaining subjects were treated with FGA medication.

${ }^{\mathrm{e}}$ Out of the 84 subjects, 13 took SGA medication at year 2, with 10 on risperidone, two on olanzapine and one on clozapine. The remaining subjects were treated with FGA medication.

${ }^{\mathrm{f}}$ Out of the 84 subjects, 15 took SGA medication at year 3, with 11 on risperidone, three on olanzapine and one on clozapine. The remaining subjects were treated with FGA medication.

significantly worse than controls in all cognitive tests, with a range from 0.4 (forward digit span) to 1.0 (logical memory, delayed recall) standard deviations below those of controls with the exception of the visual reproduction test which yielded no significant differences between the two groups. Thus, our results were comparable with the findings in the literature on cognitive impairment in patients presenting with firstepisode schizophrenia (Mesholam-Gately et al. 2009).

\section{Comparison between short and long DUP groups at each assessment time point}

As the long DUP group was found to be significantly associated with male sex in the current analysis, while pre-morbid adjustment was shown by previous studies to be related to the severity of negative symptoms (Harris et al. 2005; Jeppesen et al. 2009) and cognitive impairment (Silverstein et al. 2002), a series of ANCOVAs were performed with sex and pre-morbid functioning as covariates to control their potential confounding effects on clinical and cognitive outcomes.

\section{Symptom outcomes}

The long DUP group had significantly more negative symptoms than the short DUP group at the end of the 3-year follow-up $\left(F_{1,78}=4.1, p<0.05\right)$. There were no significant differences in negative symptom levels 
Table 2. Comparison of sociodemographics and baseline cognitive functions between patients and healthy controls

\begin{tabular}{|c|c|c|c|c|}
\hline Variable of interest & $\begin{array}{l}\text { Patients } \\
(n=93)\end{array}$ & $\begin{array}{l}\text { Controls } \\
(n=114)\end{array}$ & $\begin{array}{l}\text { Statistics: } \\
\chi^{2} \text { or } t(\mathrm{df})\end{array}$ & $p$ \\
\hline \multicolumn{5}{|l|}{ Sociodemographic characteristics } \\
\hline Mean age at entry, years (S.D.) & $31.2(9.6)$ & $33.4(10.0)$ & $1.6(205)$ & 0.11 \\
\hline Male sex, $n(\%)$ & $42(45.2)$ & $47(41.2)$ & 0.3 & 0.57 \\
\hline Mean duration of education, years (S.D.) & $10.5(2.9)$ & $11.1(2.2)$ & $1.6(205)$ & 0.11 \\
\hline \multicolumn{5}{|l|}{ Baseline cognitive functions } \\
\hline Mean WAIS-R-HK information subset (S.D.) & $14.6(5.4)$ & $17.1(4.7)$ & $3.5(205)$ & 0.001 \\
\hline Mean WAIS-R-HK digit span forward (S.D.) & $11.4(1.9)$ & $12.1(1.7)$ & $2.5(205)$ & 0.013 \\
\hline Mean WMS-R-HK logical memory, immediate recall (s.D.) & $35.1(17.0)$ & $50.6(18.9)$ & $6.1(205)$ & $<0.0001$ \\
\hline Mean WMS-R-HK logical memory, delayed recall (S.D.) & $28.3(17.5)$ & $45.2(19.6)$ & $6.4(205)$ & $<0.0001$ \\
\hline Mean WMS-HK visual reproduction, immediate recall (S.D.) & $20.2(3.4)$ & $20.7(3.2)$ & $1.2(205)$ & 0.232 \\
\hline Mean WMS-HK visual reproduction, delayed recall (s.D.) & $19.6(3.7)$ & $19.9(4.1)$ & $0.7(205)$ & 0.203 \\
\hline Mean semantic category fluency (S.D.) & $17.0(4.6)$ & $20.0(5.8)$ & $4.0(205)$ & $<0.0001$ \\
\hline Mean MWCST categories completed (S.D.) & $4.1(2.2)$ & $5.0(1.5)$ & $3.5(204)$ & 0.001 \\
\hline Mean MWCST perseverative errors (S.D.) & $6.0(7.9)$ & $3.3(3.4)$ & $-2.9(204)$ & 0.005 \\
\hline
\end{tabular}

df, Degrees of freedom; S.D., standard deviation; WAIS-R-HK, Wechsler Adult Intelligence Scale Revised (Hong Kong version); WMS-R-HK, Wechsler Memory Scale Revised (Hong Kong version); MWCST, Modified Wisconsin Card Sorting Test.

Table 3. Symptom ratings of patients with first-episode schizophrenia-spectrum disorder across 3 years of follow-up ${ }^{a}$

\begin{tabular}{lllc}
\hline $\begin{array}{l}\text { Assessment time } \\
\text { point }\end{array}$ & $\begin{array}{l}\text { Patients categorized as } \\
\text { short } v \text {. long DUP group }\end{array}$ & $\begin{array}{l}\text { PANSS positive } \\
\text { symptom score }\end{array}$ & $\begin{array}{l}\text { HEN total } \\
\text { score }\end{array}$ \\
\hline Intake evaluation & DUP $<180$ days & $20(6.2)$ & $12.2(11.5)$ \\
& DUP $\geqslant 180$ days & $19.8(4.7)$ & $14.6(11.8)$ \\
Clinical stabilization & DUP $<180$ days & $9.0(2.5)$ & $10.8(9.9)$ \\
& DUP $\geqslant 180$ days & $9.4(2.7)$ & $10.7(9.4)$ \\
Year 1 assessment & DUP $<180$ days & $8.7(3.6)$ & $8.5(8.6)$ \\
& DUP $\geqslant 180$ days & $9.3(3.1)$ & $12.8(10.5)$ \\
Year 2 assessment & DUP $<180$ days & $8.8(3.1)$ & $10.0(10.9)$ \\
& DUP $\geqslant 180$ days & $9.1(3.3)$ & $13.3(11.2)$ \\
Year 3 assessment & DUP $<180$ days & $8.9(3.9)$ & $7.7(10.0)$ \\
& DUP $\geqslant 180$ days & $9.3(3.0)$ & $12.0(13.1)^{*}$ \\
\hline
\end{tabular}

DUP, Duration of untreated psychosis; PANSS, Positive and Negative Syndrome Scale; HEN, High Royds Evaluation of Negativity Scale.

Data are given as mean (standard deviation).

a Analysis of covariance was conducted with sex and Premorbid Adjustment Scale total score as covariates.

${ }^{*} p<0.05$.

between the two groups at other time points although there was a trend indicating that patients with a long DUP exhibited a worse outcome on negative symptoms from 12 months onwards compared with those with a short DUP. The two groups did not differ in the severity of positive symptoms at all time points (Table 3).

\section{Cognitive outcomes}

There were no significant differences between the two groups in baseline cognitive measures with the exception that the short DUP group outperformed the long DUP group in the visual reproduction test (delayed recall) $\left(F_{1,76}=60.3, p<0.05\right)$. Subjects with a 


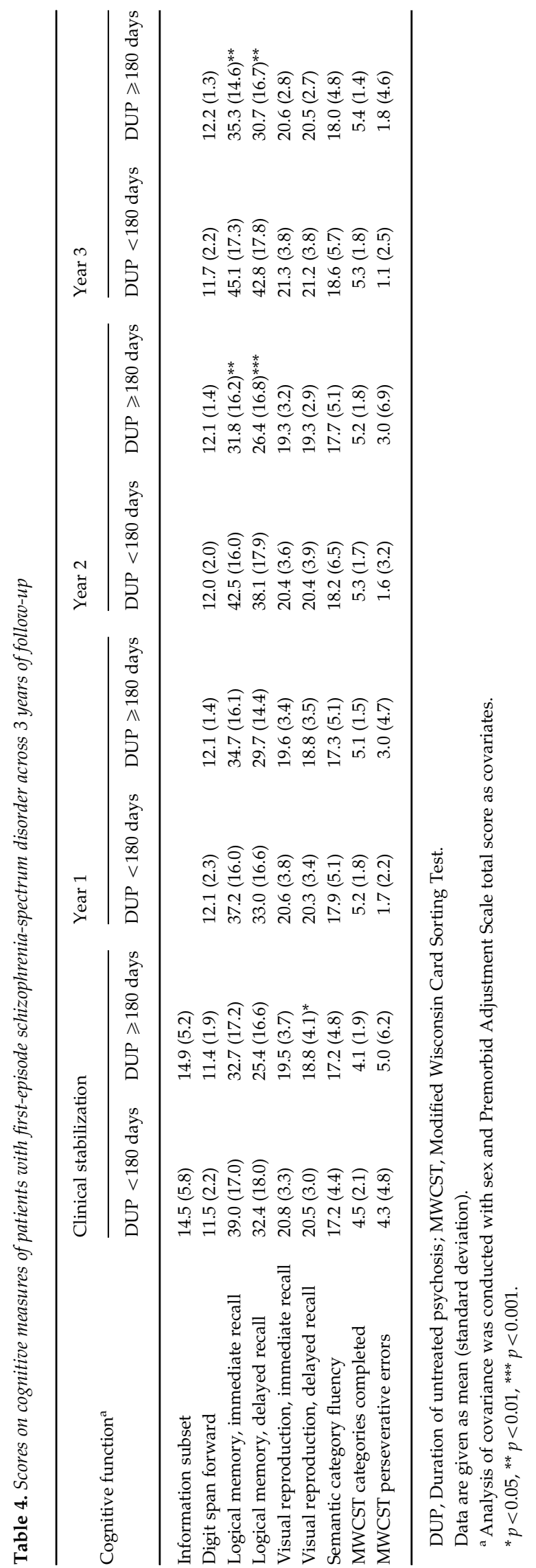

short DUP scored significantly higher in the logical memory test (both immediate and delayed recall) than those with a long DUP at 24 months (immediate recall: $F_{1,77}=12.5, p=0.001$; delayed recall: $F_{1,77}=13.5$, $p<0.001$ ) and 36 months (immediate recall: $F_{1,77}=11.0$, $p=0.001$; delayed recall: $\left.F_{1,77}=13.3, p=0.001\right)$. No significant differences were found in other cognitive measures at subsequent follow-ups (Table 4).

\section{Comparison between short and long DUP groups across the 3-year follow-up period}

\section{Symptom outcomes}

Results from a repeated-measures ANCOVA, controlling for the effects of sex and pre-morbid adjustment, showed that the main between-subject effect of DUP on negative symptoms was significant $\left(F_{1,73}=4.2\right.$, $p<0.05)$. This indicates that the short DUP group had fewer negative symptoms than the long DUP group across the 3-year follow-up period. The within-subject effect and time $\times$ group interaction did not reach statistical significance. No significant results were found for positive symptom scores for all main effect and interaction analyses.

\section{Cognitive outcomes}

The longitudinal analysis revealed a significant main between-subject effect of DUP on both immediate and delayed recall of logical memory (immediate recall: $F_{1,71}=7.4, p<0.05$; delayed recall: $\left.F_{1,71}=8.5, p<0.05\right)$. The results thus suggest that the short DUP group scored higher than the long DUP group in both immediate and delayed recall of logical memory across all time points. The interactions between DUP and logical memory were significant (immediate recall: $F_{3,213}=3.6, \quad p<0.01$; delayed recall: $F_{2.7,190.9}=4.4$, $p<0.01$ ), with the within-subject contrast test showing a significant change between 12 and 24 months after intake assessment (immediate recall: $F_{1,71}=12.4, p=$ 0.001; delayed recall: $F_{1,71}=15.4, p<0.001$ ). There was no significant within-subject effect of logical memory observed. No significant main between-subject effect of DUP on other cognitive measures or group $\times$ time interaction effect was found.

\section{Impact of DUP on cognition when negative symptoms were taken into consideration}

As our results indicated that DUP was significantly associated with the severity of both negative symptoms and logical memory impairment at 36 months, and the literature suggested that cognitive functions were correlated with negative symptoms in schizophrenia particularly on a cross-sectional basis (Harvey 
et al. 2006), Pearson correlation analysis was thus conducted to examine the relationship between logical memory and negative symptoms at 36 months. Negative symptom level was found to be significantly correlated to both immediate $(r=-0.35, p=0.001)$ and delayed $(r=-0.36, p<0.001)$ recall of logical memory. To control for the potential confounding effect of negative symptoms on memory functions, we repeated cross-sectional (ANCOVA at 36 months) and longitudinal (repeated-measures ANCOVA) analyses with logical memory as the dependent variable and negative symptom rating at 36 months as a covariate along with sex and pre-morbid adjustment. The short DUP group was found to perform significantly better than the long DUP group in logical memory at the end of the 3-year follow-up (immediate recall: $F_{1,77}=7.7$, $p<0.01$; delayed recall: $\left.F_{1,77}=9.7, p<0.01\right)$. Repeatedmeasures ANCOVA revealed a significant main between-subject effect of DUP on logical memory (immediate recall: $F_{1,71}=4.2, p<0.05$; delayed recall: $\left.F_{1,71}=5.2, p<0.05\right)$ and significant group $\times$ time interactions (immediate recall: $F_{3,207}=3.9, p<0.01$; delayed recall: $\left.F_{2.7,185.2}=4.3, p<0.01\right)$ with significant change lying between 12 and 24 months after intake assessment. Thus, associations between DUP and logical memory remained significant even when negative symptoms were taken into consideration.

\section{Discussion}

The aim of the present study was to evaluate prospectively the impact of DUP on clinical and cognitive outcomes in patients presenting with first-episode schizophrenia. Our findings indicated that patients with a short DUP showed fewer negative symptoms and more improvement in verbal memory over the 3-year follow-up period.

While the literature mostly suggests a lack of an association between DUP and negative symptoms at initial presentation in patients experiencing firstepisode schizophrenia (Addington et al. 2004; Harris et al. 2005; Jeppesen et al. 2009), results with regard to the impact of DUP on negative symptoms at follow-up are less consistent. Some investigators have posited that the observed relationship between DUP and negative symptoms may be partly spurious and confounded by pre-morbid functioning which has been shown to predict the severity of negative symptoms (Harris et al. 2005; Jeppesen et al. 2009). Our results, which are in agreement with two meta-analyses (Marshall et al. 2005; Perkins et al. 2005) and several past reports (Scully et al. 1997; Harrigan et al. 2003; Melle et al. 2008), showed that DUP predicts outcome on negative symptoms when the effect of pre-morbid adjustment is adjusted. Further, our findings revealed differential trajectories of negative symptoms in two DUP groups. We found similar levels of negative symptoms between the two groups at intake and at the time when their first psychotic episodes were stabilized with treatment. However, by the end of the first year of follow-up, there was a trend suggesting a further decrease in negative symptoms in the short DUP group and an accumulation of negative symptoms in the long DUP group, with difference in symptom severity between the two groups reaching significance at the end of the 3-year follow-up. Thus, our results provide further support to an independent contribution of DUP to clinical outcome in which schizophrenia patients with longer DUP tend to exhibit an accrual of negative symptoms over the initial 3 years after treatment initiation. In fact, some researchers have suggested that a prolonged DUP may predict the subsequent development of persistent negative symptoms (Edwards et al. 2002; Malla et al. 2004).

Consistent with previous studies (Mesholam-Gately et al. 2009), our results showed that patients with firstepisode schizophrenia had prominent cognitive impairment at baseline when compared with healthy controls. In line with most (Hoff et al. 2000; Norman et al. 2001; Ho et al. 2003; Addington et al. 2004), but not all prior reports (Joyce et al. 2002; Lappin et al. 2007), we found no significant association between DUP and most baseline cognitive functions. Two intriguing findings emerged in this study regarding the impact of DUP on longitudinal cognitive outcomes. First, among various cognitive functions, patients with a longer DUP were significantly more impaired in two specific areas, namely verbal and visual memory. Second, the effects of DUP on temporal evolution of these two memory deficits were different. A significant difference between the short and long DUP groups on visual memory was observed only at the time of clinical stabilization, with the former outperforming the latter. Conversely, patients with a longer DUP were found to have greater verbal memory impairment than those with a short DUP at the end of the second and the third years of follow-up. Thus, our findings indicate that among various cognitive domains, DUP may have a specific effect on memory function. In addition, DUP may impose short-term adverse effects on visual memory in the early phase of recovery from the first psychotic episode, while it may cause longer-term effects on verbal memory at a later stage of the recovery process. In this regard, our results were consistent with some earlier studies (Scully et al. 1997; Amminger et al. 2002) that prolonged DUP was related to worse cognitive outcomes.

It is important to note that thus far very few prospective first-episode studies have been conducted to 
examine the influence of DUP on longitudinal cognitive outcomes, and, contrary to our results, most failed to find an inverse relationship between DUP and cognitive functions at follow-up (Townsend et al. 2002; Addington et al. 2004; Rund et al. 2007; Barnes et al. 2008; Goldberg et al. 2009). One possible reason for such discrepancy may relate to the timing of assessments and length of follow-up. Those few studies that revealed negative findings had a duration of followup that ranged from 4 months to 2 years only (Townsend et al. 2002; Addington et al. 2004; Rund et al. 2007; Barnes et al. 2008; Goldberg et al. 2009). In fact, their findings of no significant relationship between DUP and cognitive impairment at 1 year after treatment initiation were replicated by our study. Thus, it raises the possibility that previous research with short study periods may fail to detect the impact of DUP on cognitive function as such a relationship may become more evident only with a longer duration of follow-up. The inconsistent findings may also be attributable to the variation of diagnostic scope and DUP of the samples studied. In particular, for those two prospective studies that had a follow-up duration of up to 2 years, both recruited subjects with diagnoses encompassing a wider spectrum of functional psychoses such as affective disorders (Rund et al. 2007) and other non-affective psychoses including delusional disorder and brief psychotic disorder (Addington et al. 2004; Rund et al. 2007) in comparison with a more narrowly defined schizophreniaspectrum disorder that was examined in our study. In addition, a cohort of one study had a relatively short median DUP [ 8 weeks in Rund et al. (2007) v. 26 weeks in Addington et al. (2004) and 180 days in this study], which may minimize the likelihood of observing an association between DUP and cognitive outcomes.

Concerning the relationship of prolonged DUP to worse cognitive outcomes, one possible explanation is that DUP may be biologically deleterious to the brain (Wyatt, 1991). There is evidence that indicates that a longer DUP is linked to greater grey matter volume reductions (Keshavan et al. 1998; Lappin et al. 2006; Bangalore et al. 2009; Malla et al. 2011), including the hippocampus (Ebdrup et al. 2010; Penttila et al. 2010), a brain region that is critically involved in the memory system (Tulving \& Markowitsch, 1998). Thus, it is plausible that a prolonged DUP may result in greater brain structural deficits with consequently more pronounced cognitive dysfunction. Nonetheless, it should be noted that results regarding the impact of DUP on brain morphology remain unclear, with some studies failing to find such a relationship (Hoff et al. 2000; Ho et al. 2003; Boonstra et al. 2011). More research should therefore be conducted to clarify the relationship between DUP and brain structural abnormalities.
Alternatively, DUP may be an epiphenomenon of prognostic factors and a marker of a subset of schizophrenia patients having poor clinical and cognitive outcomes (McGlashan, 1999). However, in the current analysis, potential confounding effects of pre-morbid adjustment and sex were adjusted and the two DUP groups showed no significant difference in current intelligence quotient (IQ) estimate. Further, the postulation that greater cognitive impairment may lead to protracted DUP via delayed effective help-seeking (Lappin et al. 2007) could not account for our findings of significant association between DUP and longitudinal cognitive outcome as the two DUP groups did not differ in most cognitive measures at baseline.

The study results have to be interpreted considering the following methodological limitations. First, measurement of DUP is inherently retrospective, with potential recall bias. We employed a structured interview incorporating multiple sources of information from patients, relatives and medical records to improve the reliability of DUP assessment. Second, cumulative active positive symptoms after treatment initiation were not measured in this study. However, unresolved positive symptoms may contribute to worse outcomes on negative symptoms and cognition, as recent studies have revealed that a longer duration of active psychosis (including both DUP and length of active psychotic state during treatment) is associated with larger grey matter volume reduction and ventricular enlargement (Cahn et al. 2009). Third, our final sample comprised slightly more females than males, which was contrary to many (Marshall et al. 2005), but not all first-episode studies (Oosthuizen et al. 2005; Ucok et al. 2006) showing male preponderance, and thus may limit the generalizability of our results. One possible reason was that we recruited patients aged from 18 to 55 years with a relatively older mean age of entry (31.2 years); therefore it may be more likely for female schizophrenia patients to be included in our study as the literature shows that females have an older age of illness onset than males and a second (though smaller) peak age of onset in their 40s (Häfner et al. 1993; Castle et al. 1998). Fourth, healthy controls were assessed once at baseline without being followed up in parallel with schizophrenia patients for 3 years; thus the magnitude of practice effect on trajectories of cognitive functions could not be addressed in this study. Fifth, the number of subjects included in this study was modest and the drop-out rate of $29 \%$ may compromise the validity of our results. The potential attrition bias may partly be minimized by the lack of significant differences between completers and non-completers with regard to sociodemographics, psychopathological scores and cognitive functions at baseline. Our drop-out rate was also comparable with 
that of several previous longitudinal first-episode studies (approximately 25-35\% within 1 to 4 years of follow-up; Harrigan et al. 2003; Clarke et al. 2006; Jeppensen et al. 2008). Nonetheless, replication by further studies with a larger sample size is warranted to confirm our findings of an independent contribution of DUP to cognitive outcome.

In conclusion, our results provided further supportive evidence that prolonged DUP is associated with worse outcomes on cognition and negative symptoms in the early phase of schizophrenia even when potential confounders including pre-morbid adjustment are controlled for. Length of untreated initial psychosis was found to exert differential effects on various cognitive domains, with deficits in memory function being most related to DUP. The impact of DUP on memory dysfunction, particularly verbal memory impairment, may only become evident at a later stage of recovery from the first psychotic episode. Owing to limited data on the relationship between DUP and cognitive impairment, more prospective research with longer follow-up duration should be conducted to clarify whether treatment delay in the first psychotic episode independently predicts longitudinal cognitive outcomes.

\section{Acknowledgements}

The study was funded by grant no. 21500.10202404 from the Research Grants Council of Hong Kong. We thank all the coordinating clinicians and staff from the psychiatric units, as well as the medical records department at the Queen Mary Hospital for their kind assistance. The authors alone are responsible for the content and writing of the paper.

\section{Declaration of Interest}

E.Y.H.C. has participated in the paid advisory board for Otsuka, received educational grant support from Janssen-Cilag, and research funding from AstraZeneca, Janssen-Cilag, Eli Lilly, Sanofi-Aventis and Otsuka.

\section{References}

Addington J, van Mastrigt S, Addington D (2004). Duration of untreated psychosis: impact on 2-year outcome. Psychological Medicine 34, 277-284.

Albus M, Hubmann W, Scherer J, Dreikorn B, Hecht S, Sobizack N, Mohr F (2002). A prospective 2-year followup study of neurocognitive functioning in patients with first-episode schizophrenia. European Archives of Psychiatry and Clinical Neuroscience 252, 262-267.
Amminger GP, Edwards J, Brewer WJ, Harrigan S, McGorry PD (2002). Duration of untreated psychosis and cognitive deterioration in first-episode schizophrenia. Schizophrenia Research 54, 223-230.

APA (1994). Diagnostic and Statistical Manual of Mental Disorders, 4th edn, revised. American Psychiatric Association: Washington, DC.

Bangalore SS, Goradia DD, Nutche J, Diwadkar VA, Prasad KMR, Keshavan MS (2009). Untreated illness duration correlates with gray matter loss in first-episode psychoses. NeuroReport 20, 729-734.

Barnes TRE, Leeson VC, Mutsatsa H, Watt HC, Hutton S, Joyce EM (2008). Duration of untreated psychosis and social function: 1-year follow-up study of first-episode schizophrenia. British Journal of Psychiatry 193, 203-209.

Boonstra G, Cahn W, Schnack HG, Hulshoff-Pol HE, Minerhoud TC, Kahn RS, van Haren NEM (2011). Duration of untreated illness in schizophrenia is not associated with 5-year brain volume change. Schizophrenia Research 132, 84-90.

Cahn W, Rais M, Stigter FP, van Haren NEM, Caspers E, Hulshoff Pol HE, Xu Z, Schnack HG, Kahn RS (2009). Psychosis and brain volume changes during the first five years of schizophrenia. European Neurospsychopharmacology 19, 147-151.

Cannon-Spoor HE, Potkin SG, Wyatt RJ (1982). Measurement of premorbid adjustment in chronic schizophrenia. Schizophrenia Bulletin 8, 470-484.

Cassidy CM, Norman R, Manchanda R, Schmitz N, Malla A (2010). Testing definitions of symptom remission in first-episode psychosis for prediction of functional outcome at 2 years. Schizophrenia Bulletin 36, 1001-1008.

Castle D, Sham P, Murray R (1998). Differences in distribution of ages of onset in males and females with schizophrenia. Schizophrenia Research 33, 179-183.

Chang WC, Chan SSM, Chung DWS (2009). Diagnostic stability of functional psychosis: a systematic review. Hong Kong Journal of Psychiatry 19, 30-41.

Chang WC, Hui CLM, Tang JYM, Wong GHY, Lam MML, Chan SKW, Chen EYH (2011). Persistent negative symptoms in first-episode schizophrenia: a prospective three-year follow-up study. Schizophrenia Research 133, 22-28.

Chen EYH, Hui CLM, Dunn ELW, Miao MYK, Yeung WS, Wong CK, Chan WF, Tang WN (2005). A prospective 3-year longitudinal study of cognitive predictors of relapse in first-episode schizophrenic patients. Schizophrenia Research 77, 99-104.

Chen EYH, Lam LCW, Chen RYL, Nguyen DGH (1996). Negative symptoms, neurological signs and neuropsychological impairments in 204 Hong Kong Chinese patients with schizophrenia. British Journal of Psychiatry 168, 227-233.

Clarke M, Whitty P, Browne S, McTigue O, Kamali M, Gervin M, Kinsella A, Waddington JL, Larkin C, O'Callaghan E (2006). Untreated illness and outcome of psychosis. British Journal of Psychiatry 189, 235-240.

Ebdrup BH, Glenthoj B, Rasmussen H, Aggernaes B, Langkilde AR, Paulson OB, Lublin H, Skimminge A, Baare W (2010). Hippocampal and caudate volume 
reductions in antipsychotic-naïve first-episode schizophrenia. Journal of Psychiatry and Neuroscience 35, 95-104.

Edwards J, Harrigan SM, McGorry PD, Amminger GP (2002). Correspondence: Norman \& Malla (2001) reviewed the literature on duration of untreated psychosis (DUP) and outcome in schizophrenia. Psychological Medicine 32, 563-564.

Elvevag B, Goldberg TE (2000). Cognitive impairment in schizophrenia is the core of the disorder. Critical Reviews in Neurobiology 14, 1-21.

Gold S, Arndt S, Nopoulos P, Leary DS, Andreasen N (1999). Longitudinal study of cognitive function in firstepisode and recent-onset schizophrenia. American Journal of Psychiatry 153, 1342-1348.

Goldberg TE, Burdick KE, McCormack J, Napolitano B, Patel RC, Sevy SM, Goldman R, Lencz T, Malhotra AK, Kane JM, Robinson DG (2009). Lack of an inverse relationship between duration of untreated psychosis and cognitive function in first-episode schizophrenia. Schizophrenia Research 107, 262-266.

Goldberg TE, Goldman RS, Burdick KE, Malhotra AK, Lencz T, Patel RC, Woerner MG, Schooler NR, Kane JM, Robinson DG (2007). Cognitive improvement after treatment with second-generation antipsychotic medications in first-episode schizophrenia: is it a practice effect? Archives of General Psychiatry 64, 1115-1122.

Green MF, Kern RS, Braff DL, Mintz J (2000). Neurocognitive deficits and functional outcome in schizophrenia: are we measuring the "right stuff"? Schizophrenia Bulletin 26, 119-136.

Häfner H, Riecher-Rossler A, Hambrecht M, Maurer K, Meissner S, Schmidtke A, Fätkenheuer B, Löffler W, an der Heiden W (1992). IRAOS: an instrument for the assessment of onset and early course of schizophrenia. Schizophrenia Research 6, 209-223.

Häfner H, Riecher-Rössler A, An der Heiden W, Maurer K, Fätkenheuer B, Löffler W (1993). Generating and testing a causal explanation of the gender difference in age at first onset of schizophrenia. Psychological Medicine 23, 925-940.

Harrigan SM, McGorry PD, Krstev H (2003). Does treatment delay in first-episode psychosis really matter? Psychological Medicine 33, 97-110.

Harris MG, Henry LP, Harrigan SM, Purcell R, Schwartz OS, Farrelly SE, Prosser AL, Jackson HJ, McGorry PD (2005). The relationship between duration of untreated psychosis and outcome: an eight-year prospective study. Schizophrenia Research 79, 85-93.

Harvey PD, Koren D, Reichenberg A, Bowie CR (2006). Negative symptoms and cognitive deficits: what is the nature of their relationship? Schizophrenia Bulletin 32, 250-258.

Ho BC, Alicata D, Ward J, Moser DJ, O'Leary DS, Arndt S, Andreasen NC (2003). Untreated initial psychosis: relation to cognitive deficits and brain morphology in first-episode schizophrenia. American Journal of Psychiatry 160, 142-148.

Hoff AL, Sakuma MR, Heydebrand G, Csernansky J, DeLisi LE (2000). Lack of association between duration of untreated illness and severity of cognitive and structural brain deficits at the first episode of schizophrenia. American Journal of Psychiatry 157, 1824-1828.

Hong Kong Psychological Society (1989a). The Wechsler Adult Intelligence Scale-Revised (Cantonese version). Hong Kong Psychological Society: Hong Kong.

Hong Kong Psychological Society (1989b). The Wechsler Memory Scale-Revised (Cantonese version). Hong Kong Psychological Society: Hong Kong.

Jeppesen P, Petersen L, Thorup A, Abel MB, Ohlenschlaeger J, Christensen TO, Krarup G, Jorgensen P, Nordentoft M (2008). The association between pre-morbid adjustment, duration of untreated psychosis and outcome in first-episode psychosis. Psychological Medicine 38, 1157-1166.

Joyce E, Hutton S, Mutsatsa S, Gibbins H, Webb E, Paul S, Robbins T, Barnes T (2002). Executive dysfunction in first-episode schizophrenia and relationship to duration of untreated psychosis: the West London Study. British Journal of Psychiatry 181 (Suppl. 43), 38-44.

Kay SR, Opler LA, Fiszbein A (1987). Positive and Negative Syndrome Scale (PANSS) for schizophrenia. Schizophrenia Bulletin 13, 261-276.

Keshavan MS, Haas GL, Kahn CE, Aguilar E, Dick EL, Schooler NR, Sweeny JA, Pettegrew JW (1998). Superior temporal gyrus and the course of early schizophrenia: progressive, static, or reversible? Journal of Psychiatric Research 32, 161-167.

Lappin JM, Morgan K, Morgan C, Hutchison G, Chitnis X, Suckling J, Fearon P, McGuire PK, Jones PB, Leff J, Murray RM, Dazzan P (2006). Gray matter abnormalities associated with duration of untreated psychosis. Schizophrenia Research 83, 145-153.

Lappin JM, Morgan KD, Morgan C, Dazzan P, Reichenberg A, Zanelli JW, Fearon P, Jones PB, Lloyd T, Tarrant J, Farrant A, Leff J, Murray RM (2007). Duration of untreated psychosis and neuropsychological function in first episode psychosis. Schizophrenia Research 95, 103-110.

Malla AK, Bodnar M, Joober R, Lepage M (2011). Duration of untreated psychosis is associated with orbito-frontal grey matter volume reductions in first episode psychosis. Schizophrenia Research 125, 13-20.

Malla AK, Norman RMG, Takhar J, Manchanda R, Townsend L, Scholten D, Haricharan R (2004). Can patients at risk for persistent negative symptoms be identified during their first episode of psychosis? Journal of Nervous and Mental Disease 192, 455-463.

Marshall M, Lewis S, Lockwood A, Drake R, Jones P, Croudace $T$ (2005). Association between duration of untreated psychosis and outcome in cohorts of firstepisode patients: a systematic review. Archives of General Psychiatry 62, 975-983.

McGlashan TH (1999). Duration of untreated psychosis in first-episode schizophrenia: marker or determinant of course? Biological Psychiatry 46, 899-907.

Melle I, Larsen TK, Haahr U, Friis S, Johannessen JO, Opjordsmoen S, Simonsen E, Rund BR, Vaglum $P$, McGlashan T (2008). Prevention of negative symptom psychopathologies in first-episode schizophrenia: two-year effects of reducing the duration of untreated psychosis. Archives of General Psychiatry 65, 634-640. 
Mesholam-Gately RI, Giuliano AJ, Goff KP, Faraone SV, Seidman LJ (2009). Neurocognition in first-episode schizophrenia: a meta-analytic review. Neuropsychology 23, 315-336.

Mortimer AM, McKenna PJ, Lund CE, Mannuzza S (1989). Rating of negative symptoms using the High Royds Evaluation of Negativity (HEN) Scale. British Journal of Psychiatry 155 (Suppl. 7), 89-92.

Nelson HE (1976). A modified card sorting test sensitive to frontal lobe defects. Cortex 12, 313-324.

Norman RMG, Townsend L, Malla AK (2001). Duration of untreated psychosis and cognitive functioning in firstepisode patients. British Journal of Psychiatry 179, 340-345.

Oosthuizen P, Emsley RA, Keyter N, Niehaus DJH, Koen L (2005). Duration of untreated psychosis and outcome in first-episode psychosis: perspective from a developing country. Acta Psychiatrica Scandinavica 111, 214-219.

Penttila M, Jaaskelainen E, Haapea M, Tanskanen P, Veijola J, Ridler K, Murray GK, Barnes A, Jones PB, Isohanni M, Koponen H, Miettunen J (2010). Association between duration of untreated psychosis and brain morphology in schizophrenia within the Northern Finland 1966 Birth Cohort. Schizophrenia Research 123, 145-152.

Perkins DO, Gu H, Boteva K, Lieberman J (2005). Relationship between duration of untreated psychosis and outcome in first-episode schizophrenia: a critical review and meta-analysis. American Journal of Psychiatry 162, 1785-1804.

Rund BR, Melle I, Friis S, Johannessen JO, Larsen TK, Midboe LJ, Opjordsmoen S, Simonsen E, Vaglum P,
McGlashan T (2007). The course of neurocognitive functioning in first-episode psychosis and its relation to premorbid adjustment, duration of untreated psychosis, and relapse. Schizophrenia Research 91, 132-140.

Scully PJ, Coakley G, Kinsella A, Waddington JL (1997). Psychopathology, executive (frontal) and general cognitive impairment in relation to duration of initially untreated versus subsequently treated psychosis in chronic schizophrenia. Psychological Medicine 27, 1303-1310.

Silverstein ML, Mavrolefteros G, Close D (2002). Premorbid adjustment and neuropsychological performance in schizophrenia. Schizophrenia Bulletin 28, 157-165.

So E, Kam I, Leung CM, Chung D, Liu Z, Fong S (2003). The Chinese-bilingual SCID-I/P Project: Stage 1: reliability for mood disorders and schizophrenia. Hong Kong Journal of Psychiatry 13, 7-18.

Townsend LA, Norman RMG, Malla AK, Rychlo AD, Ahmed RR (2002). Changes in cognitive functioning following comprehensive treatment for first episode patients with schizophrenia spectrum disorders. Psychiatry Research 113, 69-81.

Tulving E, Markowitsch HJ (1998). Episodic and declarative memory: role of the hippocampus. Hippocampus 8, 198-204.

Ucok A, Polat A, Genc A, Cakir STN (2004). Duration of untreated psychosis may predict acute treatment response in first-episode schizophrenia. Journal of Psychiatric Research 38, 163-168.

Wyatt R (1991). Neuroleptics and the natural course of schizophrenia. Schizophrenia Bulletin 17, 325-351. 